\title{
Clinicopathological Study of Cervical Tubercular Lymphadenopathy at Rajendra Institute of Medical Sciences, Ranchi
}

\author{
Dr. Rajesh Kumar Choudhary ${ }^{1}$,Dr. Pradeep Kumar $\operatorname{Singh}^{2}$,Dr. Dheeraj Kumar ${ }^{3}$ \\ ${ }^{I}$ Assistant Professor, Department of Otorhinolaryngology, Rajendra Institute of Medical Sciences, Ranchi. \\ ${ }^{2}$ Associate Professor \& Head, Department of Otorhinolaryngology, Rajendra Institute of Medical Sciences, \\ Ranchi. \\ ${ }^{3}$ Junior Resident, Department of Otorhinolaryngology, Rajendra Institute of Medical Sciences, Ranchi.
}

\begin{abstract}
:
Introduction: Tuberculosis is one of the major public health problems in India and most of the other developing countries. Tuberculosis is most common cause of death world over. The deadly synergy between Mycobacterium tuberculosis and AIDS has resulted in resurgence of tuberculosis world over. Tuberculosis is still considered a social disease; it reflects the standard of living in the community. Cervical lymphadenopathy caused by many conditions, both infective and noninfective. Out of these, tuberculosis contributes for most of the cases; hence, to tackle the commonest cause the present study was undertaken.

Material and Method: The prospective study population consisted of patients above 15 years are clinically diagnosed as cervical tubercular lymphadenitis. Patients was examined systematically giving due importance to local examination. After clinical diagnosis, further investigations were done for the confirmation of diagnosis. Treatment instituted appropriately and follow up done.

Results: Majority of cases in the study who were diagnosed clinically as cervical tubercular lymphadenitis were confirmed as tubercular by FNAC. Histopathological examination was done for cases wherever FNAC was inconclusive. Presence of constitutional symptoms had limited significance. Cervical lymph nodes group of Level-IV was most commonly affected. Variable results were noted among the groups of lesion, with regard to characteristics like size, number, laterality, levels, mobility, matting, Caseation etc. FNAC by virtue of it being inexpensive, easy to perform and quick in getting a results, is one of the important and essential diagnostic procedures.

Conclusion: Tuberculosis is an important disease, one of the commonest disease affecting lymph nodes. A constitutional symptom in cervical tubercular lymphadenitis has limited significance and clinical behavior can be highly variable. FNAC considered as frontline investigation with further investigations based on FNAC result. However, histopathological examination remains the most dependable diagnostic tool. Surgical intervention is definitely required in many cases, though; most of the cases are medically curable. Cervical tubercular lymphadenopathy is an important disease to reckon and always calls for meticulous attention, analysis and treatment.
\end{abstract}

Keywords: Cervical tubercular lymphadenopathy, FNAC, Histopathological examination

\section{Introduction}

Cervical tubercular lymphadenopathy is the most common extra pulmonary manifestation tuberculosis. In many diseases ranging from trivial inflammatory conditions to serious malignant conditions affects lymph nodes. Almost all the diseases of lymph nodes results in enlargement of nodes causing lymphadenopathy. Thus, lymph node enlargement is quite a common clinical problem.

India accounts for nearly one-third of global burden of tuberculosis. The overall prevalence of infection is about 30 per cent with rate of infection is 1-2 per cent. The prevalence of bacteriologically confirmed disease was 4 cases per 1000 population with incidence being 1.5 per 1000. Mortality rate as in 1993 is 53 per one lakh population ${ }^{1}$. Lymphadenitis is the commonest extrapulmonary manifestation of tuberculosis. Cervical TB lymphadenitis is most common type of lymphadenitis (30-51.6\%) in developing countries ${ }^{2}$.

Most of the cases of tuberculous cervical lymphadenitis are human rather than bovine in origin. In 1951 Rich and in 1957 Wilmot et al., reported that majority of tuberculous cervical lymphadenitis are caused by Human bacillus. In 1954, Wissler stated that $80 \%$ of cases of tuberculous cervical lymphadenitis is Swiss children were caused by bovine bacillus. In children, tubercular cervical lymphadenitis is mainly caused by atypical mycobacteria. In adults, it is mainly by mycobacterium tubercle bacillus ${ }^{2,3,4}$.

It is believed that local involvement of a group of nodes can lead to a state of sensitization to tuberculous bacterial protein, leading to what once called allergic tuberculous lymphadenitis. This concept may 
help to explain the excellent response of some cases of this type to the corticosteroids when used as an adjunct to specific therapy.

The presence of constitutional symptoms like fever, malaise, cough, weight loss, anorexia And loss of appetite will be present in only a small percentage of cases. A positive history of contact with tuberculosis will be present in only $10-20 \%$ of the cases.

FNAC is a simple and economic tool with high diagnostic accuracy for tuberculous lesions. The use of fine needle for cytopathological diagnosis enjoyed a meteoric rise in acceptance by both pathologists and clinicians since its resurgence in 1950. Its diagnostic accuracy approaches that of the traditional histopathology following open biopsy in many instances and sophisticated radiological imaging methods have taken the FNAC from its traditional role in investigating superficial masses to many deeply placed lesions. Thus Fine Needle Aspiration Cytology (FNAC) is proved safe, quick, reliable and cost effective procedure. In addition, it is helping in the diagnosis of lymph node tuberculosis ${ }^{5,6}$.

\section{Materials And Methodology}

The material consists of patients attending to the Rajendra Institute of Medical Sciences, Ranchi, who were diagnosed clinically as tubercular cervical lymphadenopathy. The study consists of 100 consecutive cases, which includes both outpatients and inpatients.

A detailed history was taken and note was made regarding age, sex, duration of symptoms, constitutional symptoms and history of contact with tuberculosis patient. A complete physical examination was carried out.

Inclusion criteria:

1. All patients above 15 years of age groups presenting with lymph node swelling in the cervical region.

2. Patients with enlarged neck nodes of more than two weeks duration

Exclusion criteria

1. Neck swellings other than lymph node origin.

2. Patients' below15 years of age groups.

3. Patients with enlarged neck nodes of less than two weeks duration.

\section{Results}

Statistical Analysis: The data was analyzed by using SPSS 20 software. The data is presented in percentages, rates and ratios. Chi square test was used to find the association between attributes.

Out of 100 cases which were clinically diagnosed as cervical tubercular lymphadenitis 80 cases were confirmed as tubercular lymphadenitis, 15 cases turned out as reactive lymphadenitis, 3 cases reported as Lymphoma and 2 cases were found to have Metastatic secondary's. Confirmed tubercular lymphadenitis cases were analyzed further.

Age distribution: In the present study, it was observed that, the disease commonly affected second and third decades with $22.5 \%$, and $45 \%$ respectively. The next common group was fourth decade which is $18.75 \%$ followed by fifth and sixth decade with $10 \%$ and $2.5 \%$ respectively. Only $1.25 \%$ affected among above 60 years of age group.

Table - I: Age distribution

\begin{tabular}{|c|c|c|}
\hline Age group (years) & Number of cases (N=80) & Percentage \\
\hline $15-20$ & 18 & 22.5 \\
\hline $21-30$ & 36 & 45 \\
\hline $31-40$ & 15 & 18.75 \\
\hline $41-50$ & 08 & 10 \\
\hline $51-60$ & 02 & 2.5 \\
\hline$>60$ & 01 & 1.25 \\
\hline Total & 80 & 100 \\
\hline
\end{tabular}

Sex distribution: In the present study, female preponderance was seen. It was observed that $55 \%$ of cases were females and males being $45 \%$. The male female ratio was 1:1.24. Indeed the female predilection has been observed by most of the studies.

Table - II: Sex distribution

\begin{tabular}{|c|c|c|}
\hline Sex & Number of cases $(\mathrm{N}=80)$ & Percentage \\
\hline Male & 34 & 42.5 \\
\hline Female & 46 & 57.5 \\
\hline
\end{tabular}

Constitutional symptoms: In the present study, it was observed that 20 cases $(30.7 \%)$ had constitutional symptoms. Among which six cases had only fever, and 14 cases had more than one symptom, which include loss of weight. 
Table - III: Constitutional symptoms

\begin{tabular}{|c|c|c|}
\hline Constitutional symptoms & Number of cases $(\mathrm{N}=80)$ & Percentage \\
\hline Absent & 59 & 73.75 \\
\hline Present & 21 & 26.25 \\
\hline
\end{tabular}

Site distribution of Cervical Tubercular lymphadenopathy: In the present study, Lymph node groups of LevelIV was the commonest site involved accounting for 24 cases $(30 \%)$. The next commonest was Level-V involving 20 cases $(25 \%)$. Level-III involving $15(18.75 \%)$ cases, $10(12.5 \%)$ cases involved in Level-I, 5 $(6.25 \%)$ cases involved in more than one Level of the neck, which includes bilateral involvement which is added to predominant side. And 6 (7.5\%) cases involved in Level-II.

Table - IV: Site distribution of Cervical Tubercular lymphadenopathy

\begin{tabular}{|c|c|c|c|c|c|c|}
\hline \multirow{3}{*}{$\begin{array}{l}\text { Site distribution of Cervical } \\
\text { Tubercular lymphadenopathy }\end{array}$} & \multicolumn{4}{|c|}{ Side of neck } & \multicolumn{2}{|c|}{ Total } \\
\hline & \multicolumn{2}{|c|}{ Right } & \multicolumn{2}{|c|}{ Left } & \multirow[t]{2}{*}{ Number } & \multirow[t]{2}{*}{$\%$} \\
\hline & Number & $\%$ & Number & $\%$ & & \\
\hline Level-I & 08 & 10 & 02 & 2.5 & 10 & 12.5 \\
\hline Level-II & 04 & 5 & 02 & 2.5 & 06 & 7.5 \\
\hline Level-III & 10 & 12.5 & 05 & 6.25 & 15 & 18.75 \\
\hline Level-IV & 17 & 21.25 & 07 & 8.75 & 24 & 30 \\
\hline Level-V & 12 & 15 & 08 & 10 & 20 & 25 \\
\hline More than one level & 03 & 3.75 & 02 & 2.5 & 05 & 6.25 \\
\hline Total & 54 & 67.5 & 26 & 32.5 & 80 & 100 \\
\hline
\end{tabular}

Distribution of FNAC findings of patients studied: In the present study of 100 cases, 85\% (68) of cases were confirmed the diagnosis as tubercular lymphadenitis by FNAC alone. In addition, another 15\% (12) of cases were inconclusive with the FNAC were subjected to Histopathological examination for the confirmation of the diagnosis. Remaining 20 out of 100 cases were non-tubercular.

Table - V: Distribution of FNAC findings of patients studied

\begin{tabular}{|c|c|c|}
\hline FNAC findings & Number of cases $(\mathrm{N}=100)$ & Percentage \\
\hline Tuberculous Lymphadenitis & 68 & 68 \\
\hline Reactive Lymphadenitis & 12 & 12 \\
\hline Lymphoma & 02 & 2 \\
\hline Metastatic & 01 & 1 \\
\hline Inconclusive & 17 & 17 \\
\hline
\end{tabular}

Table - VI: Distribution of Histopathological diagnosis of patients of inconclusive based on FNAC

\begin{tabular}{|c|c|c|}
\hline HPE findings & Number of cases $(\mathrm{N}=17)$ & Percentage \\
\hline Tuberculous Lymphadenitis & 12 & 70.6 \\
\hline Reactive Lymphadenitis & 03 & 17.6 \\
\hline NH Lymphoma & 01 & 5.9 \\
\hline Metastatic & 01 & 5.9 \\
\hline
\end{tabular}

\section{Discussion}

Age distribution: In my series of 65 cases, the disease commonly affected second and third decades with $22.5 \%$, and $45 \%$ respectively. Followed by fourth and fifth decade which is $18.75 \%$ and $10 \%$ respectively. Similar incidence was observed in study conducted by Memish Z. A.et al ${ }^{7}$, Kishore C Prasad Et $\mathrm{al}^{8}$ and Subrahmanyam $\mathrm{M}^{9}$ Ruchi Kajura $\mathrm{K} \mathrm{C}^{10}$.

Sex distribution: A female predilection was also observed in the studies by Ruchi Kajura $\mathrm{K} \mathrm{C}^{10}$ and Mehmet F Oktay et al $^{11}$, Bedi R S, et al $^{12}$ with male female incidence ratio being 146:197 (1:1.3), 24:49(1:2) and 29:48(1:1.7) respectively.

Constitutional symptoms: In the present study, 21 cases $(26.25 \%)$ had constitutional symptoms. Observations were made by Sharma M. et $\mathrm{al}^{13}$ showed $41.7 \%$, Memish Z. A.et al ${ }^{7}$, Showed $36 \%$ and Jha BC et $\mathrm{al}^{14}$ showed $35.7 \%$ of constitutional symptoms anorexia which is nearly similar to Present study.

Site distribution of Cervical Tubercular lymphadenopathy: In present study the commonest site involved was Lymph node groups of Level-IV accounting for 24 cases (30\%). bilateral involvement which is added to predominant side. Similar findings have been observed by the studies of Mehmet F Oktay et al ${ }^{11}$.

Distribution of FNAC findings of patients studied: In the present study, out of 100 cases, $80 \%$ of cases were found to have tubercular pathology. Similar findings were observed in a studies of Purohit S D et $\mathrm{al}^{15}$, Bedi R S. et $\mathrm{al}^{12}$. In the present study, it was observed that, 68 cases were diagnosed by FNAC alone and 12 cases by Biopsy which were inconclusive with FNAC study. Nearly similar observation were made by Kishore 
C Prasad $\mathrm{Et} \mathrm{al}^{8}$, who observed $92 \%$ of were diagnosed by FNAC and inconclusive cases were subjected to biopsy, of which $8 \%$ of total positive cases were confirmed as tubercular.

\section{Conclusion}

Tuberculosis is an important disease, one of the commonest disease affecting lymph nodes. It is curable with anti tubercular drugs if administered according to WHO guidelines under RNTCP.

A constitutional symptom in cervical tubercular lymphadenitis has limited significance and clinical behavior can be highly variable.

FNAC deemed as frontline investigation with further investigations based on FNAC result. However, histopathological examination remains the most dependable diagnostic tool.

\section{References}

[1]. Singh IB and Pal GP. Human Embryology, 7th Edition, 2001; 265-266.

[2]. Surendra K Sharma. Textbook of Tuberculosis. 2nd edn;2009

[3]. Cantrell. R.W. at al. Diagnosis and management of tubercular cervical lymphadenitis. Arch Otolaryngology. Jan1975; 101:53-55

[4]. Sloane M F. Mycobacterial lymphadenitis OMW Garayn Tuberculosis. IED 1996;577-582.

[5]. M. Minor Madakour, Kitab E ,AL-Otaibi, R. AL Swailem. Text book of Tuberculosis. Page no, 15-26 \& 153-160.

[6]. Leong Anthony SY and Craig L James. Cytological specimen. Hand book of surgical pathology, 1st edn 1996: 205-209

[7]. Memish Z. A.et al, Clinico-diagnostic experience with tuberculous lymphadenitis in Saudi Arabia Clinical Microbiology and Infection, Volume 6 Number 3, March 2000

[8]. Kishore C Prasad Et al. The Journal of Laryngology \& Otology / Volume 121 / Issue 10 / October 2007, pp 979 985

[9]. Subrahmanyam M.Role of surgery and chemotherapy for peripheral lymph node tuberculosis Br. J. Surg. 1993, Vol. 80, December 1547- 1548

[10]. Ruchi Khajuria, K C, et al. Pattern of lymphadenopathy on FNAC in Jammu. Vol-8, no-3; July-Sept 2006.

[11]. Mehmet F Oktay et al. The Journal of Laryngology \& Otology Followup results in tuberculous cervical lymphadenitis / Volume 120 / Issue 02 / February 2006, pp 129-132

[12]. Bedi RS et al. Clinicopathological study of superficial lymphadenopathy in northern India. Ind J TB 1987;34:189-191.

[13]. Sharma M. et al, Spectrum of cytomorphology of tuberculous lymphadenitis and changes during anti-tubercular treatment: University College of Medical Sciences, Delhi, India; DOI:10.1111/j.1365-2303.2007.

[14]. Jha BC et al, cervical TB lymphadenopathy: changing clinical pattern and concept in management; Postgrad Med J. 2001 Mar;77(905):185-7.

[15]. Purohit S D. et al. A novel clinical scoring method for diagnosis of tubercular cervical lymphadenitis. Ind. J. Tub., 1987, 34, 22. 